\title{
GOVERNANÇA TRANSNACIONAL DA INTERNET: COOPERAÇÃO INTERNACIONAL OU PRIVATIZAÇÃO?
}

\author{
GOBERNANZA TRANSNACIONAL DE INTERNET: ¿COOPERACIÓN \\ INTERNACIONAL O PRIVATIZACIÓN?
}

\section{INTERNET TRANSNATIONAL GOVERNANCE: INTERNATIONAL COOPERATION OR PRIVATIZATION?}

Jaqueline Trevisan PIGATTO ${ }^{1}$

RESUMO: Este artigo busca contextualizar um período de transição na governança global da Internet. Com o caso Snowden em 2013, fortaleceu-se a autorregulação privada, mas no médio prazo o Estado respondeu com a criação de leis e medidas de constrangimento ao setor privado, especialmente na questão de proteção de dados pessoais e após o caso Cambridge Analytica, em 2018. Ainda mantendo uma preponderância na governança multissetorial, o setor privado agora está sujeito a regulações e procura se aliar aos Estados para uma possível corregulação de algumas de suas atividades na Internet.

PALAVRAS-CHAVE: Governança da internet. Transnacional. Regulação.

RESUMEN: Este artículo busca contextualizar un periodo de transición en la gobernanza global de Internet. Con el caso Snowden en 2013, se fortaleció la autorregulación privada, pero a medio plazo el Estado respondió con la creación de leyes y medidas para restringir el sector privado, especialmente en materia de protección de datos personales y después del caso Cambridge Analytica, en 2018. Aún manteniendo una preponderancia en la gobernanza multisectorial, el sector privado ahora está sujeto a regulaciones y busca aliarse con los Estados para una posible corregulación de algunas de sus actividades en Internet.

PALABRAS CLAVE: Gobernanza de internet. Transnacional. Regulación.

ABSTRACT: This article seeks to contextualize a period of transition in global Internet governance. With the Snowden case in 2013, private self-regulation was strengthened, but in the medium term the State responded with the creation of laws and measures to restrict the private sector, especially in the matter of personal data protection and after the Cambridge Analytica case, in 2018. Still maintaining a preponderance in multistakeholder governance, the private sector is now subject to regulations and seeks to ally itself with States for possible coregulation of some of its activities on the Internet.

KEYWORDS: Internet governance. Transnational. Regulation.

\footnotetext{
${ }^{1}$ Universidade Estadual Paulista (UNESP), Araraquara - SP - Brasil. Doutoranda em Ciências Sociais. ORCID: https://orcid.org/0000-0003-0690-1064. E-mail: jaquetpigatto@gmail.com
} 


\section{Introdução}

A Internet tem provocado, ao longo de seus quase 30 anos de presença nas vidas das pessoas, embates entre seus usuários finais, corporações que criam e moldam espaços online e governos que permitem, em diferentes graus, o funcionamento desse meio de comunicação e informação. Após um período onde poucos ainda tinham acesso à rede, como na década de 1990, e o anonimato prevalecia entre os usuários, movidos por interesses comuns como em websites de jogos, música e temas diversos, o advento das redes sociais impulsionado pela criação do Facebook em 2004 transformou o uso da rede. Agora, a Internet se torna um ambiente sem espaço para anonimato: o rosto e informações dos usuários são pré-requisitos para socializar, se comunicar, buscar um emprego ou um serviço onde se vive.

Passando para a década de 2010, grandes corporações criaram serviços personalizados que se tornaram parte vital do cotidiano, seja leitura de notícias, mapeamento de lugares, serviços financeiros, comércio, comunicação instantânea, entre muitas outras possibilidades. Dessa maneira, a Internet se tornou um ambiente cada vez mais complexo, com base na exploração de dados pessoais, criação de conteúdo (desde o mais útil até o fenômeno da desinformação) e disputa de mercado. O Estado tardou a adentrar o campo da governança da rede, mas desde o caso Snowden em 2013, esse quadro tem se alterado aos poucos, culminando em uma mistura de regulações estatais com autorregulação privada, enquanto a sociedade civil ainda tenta ser ouvida, mas já com algumas conquistas relevantes.

Entendemos "governança" como um conjunto de regimes compostos por atores diversos, onde a autoridade se estende para além do ator estatal, sendo assim descentralizada e predominando medidas não-coercitivas como princípios e diretrizes não vinculantes (ROSENAU, 1992; RADU et al., 2014). Essa abordagem para o campo da Internet acabou por se ramificar em duas vertentes: de um lado, Estados que defendem o caráter multilateral, ou seja, a tomada de decisões e participação efetiva apenas de países e de preferência vinculado ao sistema da Organização das Nações Unidas (ONU), casos de China e Rússia; enquanto outros países como Estados Unidos, membros da União Europeia e o Brasil defendem o caráter multissetorial, onde Estados dividem a arena de debates e tomadas de decisões com outros atores que compõem a Internet, ou seja, setor privado, academia, comunidade técnica e a sociedade civil.

Este artigo mostra que a depender de contextos específicos, o papel da regulação estatal aumentou com o passar do tempo. Porém, a governança da Internet tende a ser moldada por ações de grandes corporações transnacionais, donas de plataformas que possuem bilhões de 
usuários mundialmente. Enquanto grande parte da comunidade da Internet (comunidade epistêmica, sociedade civil e setor privado) preza por uma governança com princípios e normas acordados por consenso e seguidos voluntariamente por atores, o Estado trouxe uma abordagem mais voltada à regulação: imposição de leis e centralidade no poder soberano.

Tal quadro se deve a dois casos recentes tidos neste trabalho como críticos para o desenvolvimento da governança da Internet: o caso Snowden, em 2013, intensificou os debates acerca da dualidade privacidade versus segurança, colocando em xeque o papel do Estado e das atividades de vigilância, favorecendo assim medidas de autorregulação por parte das plataformas da Internet. Já o caso da Cambridge Analytica em 2018, onde dados pessoais de usuários do Facebook foram utilizados sem autorização dos mesmos para guiar campanhas eleitorais, inverteu a lógica de 2013, no sentido de que aqui o setor privado quebrou a confiança para com seus usuários. Tal caso levou a União Europeia, em maior medida, e os Estados Unidos, em menor medida, a questionarem o funcionamento da plataforma, assim como influenciou o Brasil a aprovar, após anos de debate e tentativas de formulação, sua própria lei de proteção de dados. Não se ignora, também, o caso da eleição de Donald Trump em 2016, onde o controle de conteúdo na Internet passou a ser mais questionado pelos Estados.

\section{A dúvida do multissetorialismo}

Autores como Scherer et al., (2006) ressaltam a necessidade de adaptação do Estado nesse novo contexto de reconfiguração proveniente da globalização, onde há divisão de espaço, poder e autoridade com atores não-estatais. Corporações transnacionais estão passando a ocupar funções antes desempenhadas pelo Estado, tendo sua importância aumentado nas sociedades, assim como suas responsabilidades e participação política, especialmente na implementação de padrões, regras e práticas. Em muitos casos, as transnacionais assumiram um papel de resposta às necessidades e expectativas sociais. Vale recordar que, embora haja uma concentração de poder pelas grandes corporações, seus serviços também distribuíram certo poder para seus usuários, facilitando comunicação, informação e organização de dados pessoais. Embora plataformas como Facebook e WhatsApp tenham sido utilizadas de modo mal intencionado para influenciar eleições políticas ${ }^{2}$, elas também permitem facilidades em um contexto democrático, como aproximação entre eleitor e representante político, comunicação e acesso à

${ }^{2}$ Sobre o disparo de mensagens automatizadas pelo WhatsApp nas eleições brasileiras de 2018, ver: MELLO, P. WhatsApp admite envio maciço ilegal de mensagens nas eleições de 2018. Folha, 8 out. 2019. Disponível em: https://www1.folha.uol.com.br/poder/2019/10/whatsapp-admite-envio-massivo-ilegal-de-mensagens-naseleicoes-de-2018.shtml. Acesso em: 4 fev. 2020. 
informação. Ou seja, essas tecnologias podem ser utilizadas tanto para um progresso democrático e da sociedade em geral, quanto para prejudicá-la.

Diante da pluralidade de atores e das diferentes abordagens dos países (Estados Unidos, União Europeia e China, por exemplo), o termo "governança global” não parece tão apropriado, mas sim o da "governança transnacional”. Como colocam Gomes e Merchán (2016, p. 90, grifo nosso):

Pode-se argumentar que é justamente para destacar este emaranhado de relações entre atores públicos (i.e., Estado, suas organizações e agências) e privados (i.e., corporações, movimentos sociais, organizações não governamentais ou organismos multilaterais) - que tornam as fronteiras entre Estado e mercado nebulosas, que prefere-se o termo transnacional ao global, pois o último tende a unificar estas relações ao redor da ideia do global único, diminuindo a importância das particularidades contextuais, sendo essa uma das distinções entre a governança global e transnacional (GOMES; MERCHÁN, 2016, p. 90, grifo nosso).

O que ocorre é que o cenário da governança da Internet em temas de políticas públicas ainda não toma decisões vinculantes na mesma medida em que provocam debates multissetoriais, caso do Fórum de Governança da Internet (IGF) ${ }^{3}$. Então entra-se no debate sobre regulação e a necessidade de intervenção do Estado, para contrabalancear a preponderância do setor privado e sua autorregulação. A mudança de discurso do próprio CEO do Facebook, Mark Zuckerberg, evidencia essa transformação: em março de 2014, ainda durante os desdobramentos do caso Snowden, Zuckerberg postou em sua rede social:

A internet funciona porque a maioria das pessoas e empresas faz o mesmo. Trabalhamos juntos para criar esse ambiente seguro e tornar nosso espaço compartilhado ainda melhor para o mundo. É por isso que fiquei tão confuso e frustrado com os repetidos relatos do comportamento do governo dos EUA. Quando nossos engenheiros trabalham incansavelmente para melhorar a segurança, imaginamos que estamos protegendo você contra criminosos, e não nosso próprio governo. O governo dos EUA deve ser o campeão da internet, não uma ameaça. Eles precisam ser muito mais transparentes sobre o que estão fazendo, caso contrário, as pessoas acreditarão no pior. [...] Então, cabe a nós - todos nós - construir a internet que queremos. Juntos, podemos construir um espaço que é maior e uma parte mais importante do mundo do que qualquer coisa que temos hoje, mas que também é seguro. Estou empenhado em ver isso acontecer, e você pode contar com o Facebook para fazer a nossa parte. (ZUCKERBERG, 2014, grifos nossos, tradução nossa).

${ }^{3}$ O Fórum de Governança da Internet (IGF) ocorre anualmente desde 2006, reunindo Estados, setor privado, comunidade técnica, acadêmicos e qualquer interessado no ecossistema digital. Sem tomada de decisões vinculantes, o Fórum serve como um grande espaço de diálogo e troca de conhecimentos e experiências em escala global, voltando sua atenção para temas de políticas públicas, desenvolvimento econômico e social, além de temas emergentes como Inteligência Artificial e Cidades Inteligentes. Para mais informações: https://www.intgovforum.org/multilingual/. Acesso em: mar. 2019. 
Já em março de 2019, um ano após o caso da Cambridge Analytica ser revelado, Zuckerberg escreveu em sua página no Facebook:

\begin{abstract}
Eu acredito que precisamos de um papel mais ativo para governos e reguladores. Atualizando as regras para a Internet, podemos preservar o que há de melhor nela - a liberdade para as pessoas se expressarem e para empreendedores construírem coisas novas - enquanto também protege a sociedade de danos mais amplos. [...] privacidade efetiva e proteção de dados precisam de uma configuração global harmonizada. Pessoas no mundo todo pediram por uma regulação de privacidade compreensível de acordo com a Regulação Geral de Proteção de Dados da União Europeia, e eu concordo. Acredito que seria bom para a Internet se mais países adotassem regulações como a GDPR em uma configuração comum. (ZUCKERBERG, 2019, grifos nossos, tradução nossa).
\end{abstract}

Sem aprofundar muito em teorias de regulação, voltamos nossa atenção para a ideia de regulação responsiva, onde há certa flexibilidade acerca da necessidade de intervenção: "The basic idea of responsive regulation is that governments should be responsive to the conduct of those they seek to regulate in deciding whether a more or less interventionist response is needed" (BRAITHWAITE apud GOETTENAUER, 2019, p. 135).

Estabelecendo então uma ideia de cooperação e de intervenções graduais a depender da necessidade de coerção ou não para com os regulados, Goettenauer (2019) identifica três elementos para a regulação responsiva, sendo eles 1) uma convergência de modelos regulatórios que favoreçam a cooperação entre regulador e regulado; 2) uma estrutura de pirâmide onde a base é um regime de autorregulação, mas o topo traz punições e intervenções mais graves por parte do regulador; e 3) a presença de terceiras partes no debate regulatório.

Aliamos a essa regulação responsiva a ideia de diferentes graus de multissetorialismo, algo que já acontece em certa medida, especialmente no campo de proteção de dados. Afinal, as empresas possuem ações de autorregulação aplicadas a todo momento, já embutidas nas políticas de suas plataformas ${ }^{4}$. Porém, o Estado que aplica uma lei de proteção de dados pessoais também estabelece diretrizes e intervém (através de aplicação de multa) quando necessário. É o caso da União Europeia e sua Regulação Geral de Proteção de Dados (GDPR), que se tornou um forte instrumento de notificação de violação das plataformas para com os

${ }^{4}$ Sobre os termos de política e privacidade das plataformas, ver: OBAR, J.; OELDORF-HIRSCH, A. The biggest lie on the internet: ignoring the privacy policies and terms of service policies of social networking services. The 44th Research Conference on Communication, Information and Internet Policy, 2018. Disponível em: https://papers.ssrn.com/sol3/papers.cfm?abstract_id=2757465. Acesso em: 20 mar. 2019. 
dados pessoais de seus usuários. O Brasil aprovou lei semelhante em 2018, mas que ainda não entrou em vigor ${ }^{5}$.

Essa visão apresenta potencial para ser aprimorada e percebe-se uma busca por essa corregulação pelos debates no IGF. Dentre os principais problemas a serem solucionados, podemos notar 1) a falta de leis nos Estados Unidos (país natal de grandes corporações como Google, Facebook e Microsoft), assim como uma fragmentação sobre o entendimento das múltiplas funções das plataformas onde podem ser aplicadas leis de proteção ao consumidor, leis antitruste e leis de privacidade, por exemplo; 2) a necessidade de alinhamento/harmonização de marcos regulatórios, onde a Europa já busca isso e é evidente na participação de reguladores no IGF, também os BRICS (grupo de países tido como emergentes na década de 2000 composto por Brasil, Rússia, Índia, China e África do Sul) apresentam potencial para tal alinhamento ${ }^{6}$; e 3 ) o entendimento ou a falta de conhecimento de políticos e legisladores sobre as plataformas e o uso das novas tecnologias de modo geral, a exemplo de que mesmo no Brasil, com seu histórico de destaque no tema da governança da Internet, já houveram tentativas de alteração do principal marco regulatório existente e modelo internacional, o Marco Civil da Internet.

Portanto, temos que o multissetorialismo funciona ao priorizar agendas, debates, incluir a sociedade civil, acadêmicos, técnicos e outros atores interessados, mas a pressão por decisões fica dependente dos atores mais poderosos - aqui tanto as grandes empresas quanto Estados que tenham um poder de enforcement, como é o caso da União Europeia. Tal abordagem faz parte da governança, que pode abranger tanto mecanismos informais quanto formais, ainda que no caso da Internet, exista uma preferência por ações voluntárias, livres de algum tipo de coerção.

\section{A preponderância do setor privado}

O problema de formular e aplicar regulação é, como apontado por Hurrell (2007), a dependência de atores preponderantes para aplicá-las com efetividade. Um país de pouca relevância no sistema internacional ou uma pequena plataforma digital dificilmente

${ }^{5}$ Com previsão de entrada em vigor para agosto de 2020, a LGPD enfrenta controvérsias acerca da criação de sua Autoridade Nacional de Proteção de Dados, prevista na lei como um órgão independente para a fiscalização do cumprimento dela, mas na prática possuindo uma vinculação excessiva com o Poder Executivo. Para mais detalhes, ver: TEFFÉ, C. Por que precisamos de uma Autoridade Nacional de Proteção de Dados? Jota, 7 jan. 2020. Disponível em: https://www.jota.info/opiniao-e-analise/artigos/por-que-precisamos-de-uma-autoridade-nacionalde-protecao-de-dados-07012020. Acesso em 4 fev. 2020.

${ }^{6}$ De acordo com Belli (2019), o momento é propício para um alinhamento de marcos regulatórios entre os membros dos BRICS, já que todos os integrantes do grupo adotaram recentemente ou estão finalizando marcos normativos em relação à proteção de dados pessoais, visando maior segurança para o ecossistema digital. 
conseguiriam estabelecer um princípio ou norma que fosse aplicada por muitos atores e de maneira eficiente. Diferentemente, a União Europeia possui capital político e influência sobre outros atores para aplicar suas leis, assim como grandes corporações como Facebook detém poder suficiente para, a partir de suas ações, influenciar o mercado e as estratégias regulatórias em diferentes países. No caso da governança da Internet, tais ações entram em um contexto previamente dominado pelos Estados Unidos, seus poderes político e econômico e sua ideologia de não-intervenção para priorização do mercado, que se internacionalizou e agora enfrenta uma demanda por mudanças.

É nesse contexto que vemos o período pós-Snowden como um período de transição na governança da Internet, de uma preponderância do setor privado (restrito às grandes corporações) e de um momento de fortalecimento do multissetorialismo, a exemplo da criação do Marco Civil da Internet brasileiro, para uma união mais forte do multissetorialismo com o multilateralismo, no que chega em 2018 (ano da entrada em vigor da GDPR) como um momento de transformação, para um surgimento mais forte de ações estatais, agora protagonizadas pela União Europeia. Se haverá preponderância desse ator sobre o setor privado, uma futura agenda de pesquisa se mostra vital nesse acompanhamento, mas por ora ainda se pode vislumbrar a forte permanência das grandes transnacionais americanas, com certa independência e até liderança em diversos temas do ecossistema digital.

Como apontam Hurel e Lobato (2018), o caso da Microsoft é um forte exemplo de ação privada no sistema internacional, na medida em que a empresa advoga diplomaticamente pela implementação de normas no campo da segurança cibernética, junto a Estados e outros atores internacionais. As autoras argumentam que essa gigante americana tomou a liderança para formulação de normas que visam a estabilidade e segurança do ciberespaço, ainda em diferentes níveis como no nacional e global:

[...] os Centros de Transparência, a proposta da Convenção Digital de Genebra, e serviços de suporte técnico (como os serviços em nuvem) integram a abordagem sociotécnica e multifacetada da companhia para regular segurança cibernética. Tecnicamente, esse engajamento acontece através de respostas à incidentes, operações de remoção de botnets e suporte técnico. Politicamente, por meio de atividades de normas empreendedoras estabelecidas por sua "Equipe de Estratégia e Diplomacia de Segurança Global", bem como por iniciativas internacionais como a Comissão Global sobre a Estabilidade do Ciberespaço (GCSC). Nesse sentido, os Centros de Transparência compreendem aspectos nacionais e regionais do envolvimento da empresa e lidam diretamente com a questão da segurança e resiliência da infraestrutura. A Equipe de Diplomacia da Microsoft, por outro lado, se engaja na promoção de cibernormas "multilaterais" globais com uma implementação de "várias partes interessadas", advogando, assim, por um maior 
compromisso governamental com a governança global de segurança cibernética e o empreendedorismo de normas. (HUREL; LOBATO, 2018, p. 3, grifos nossos, tradução nossa).

Outro destaque recente de ação privada é a implementação de um Comitê de Supervisão pelo Facebook (Facebook Oversight Board), tido pela própria empresa como independente, com o objetivo de avaliar casos específicos de controle de conteúdo e uso de dados pessoais, reportados por qualquer usuário da rede social. A previsão é de que o Comitê seja composto por quarenta membros, com mandatos de três anos, onde o Facebook nomeará um grupo inicial que posteriormente selecionará os demais membros, seguindo critérios de diversidade (HARRIS, 2019). Segundo o CEO Mark Zuckerberg, os Padrões da Comunidade seguem uma série de valores - autenticidade, segurança, privacidade e dignidade - guiados pelos padrões internacionais de Direitos Humanos. Assim, o Comitê será um mecanismo para que se possa recorrer de decisões da plataforma.

A implementação desse corpo independente passou por fases de consulta pública e a empresa diz estar trabalhando a partir dos feedbacks recebidos. As decisões do Comitê serão implementadas de imediato e ele poderá fazer recomendações de políticas ao Facebook. Desse modo, será interessante observar como esse mecanismo funcionará na prática e como irá dialogar com a governança global multissetorial, pois caso seja bem sucedido, intermediando o poder da plataforma para com o usuário e as leis regulatórias estatais em vigor, poderá se tornar uma nova estrutura de governança institucionalizada para grandes plataformas digitais. Mais do que isso, sua estrutura e funcionamento podem inovar a maneira de lidar com problemas transnacionais da Internet, ainda que levante questionamentos sobre legitimidade e participação multissetorial. A governança da Internet, assim, permanece um campo de experimentação institucional para as relações transnacionais contemporâneas.

A mudança de discursos também ocorre por parte do setor governamental e de organizações internacionais, a exemplo do discurso de abertura do IGF 2018 onde o presidente Macron não utilizou o termo "multissetorial" mas sim falou de um "novo multilateralismo", ou seja, ele prioriza o envolvimento de Estados para regulação, sem enfatizar a participação de outros setores. O secretário geral da ONU, Antonio Guterres, também argumentou em favor do multilateralismo na apresentação do relatório de cooperação digital da organização em 2019.

Basta pensarmos nos casos asiáticos para vermos que o multilateralismo já é fortemente presente na condução do ciberespaço, onde países como China e Rússia veem uma tendência de espelhar na Internet suas fronteiras nacionais, caso por exemplo da Grande Muralha Digital 
chinesa $^{7}$, que exerce forte censura sobre a Internet dentro do seu território. Também na China, o controle governamental opera rigidamente sobre as grandes corporações locais, que buscam se expandir internacionalmente, ao mesmo tempo em que a entrada de plataformas como Google e Facebook é restringida. Dados mostram uma tímida presença de algumas dessas companhias chinesas no $\mathrm{IGF}^{8}$, enquanto a China já realiza sua própria conferência para a Internet, chamada simplesmente de Conferência Mundial da Internet (WIC), onde em sua quarta edição no ano de 2017, foi anunciada uma cooperação entre o Estado chinês e Arábia Saudita, Egito, Turquia, Tailândia, Laos, Sérvia e Emirados Árabes Unidos, na área de economia digital (PATRICK; FENG, 2018). É esse cenário de "soberania digital" que a União Europeia parece querer evitar, ao mesmo tempo em que combate a total liberdade de intervenção estadunidense. O "novo multilateralismo" europeu, portanto, estaria entre os modelos americano e asiático, onde a participação da sociedade civil ainda é questionável.

Tal configuração de cooperação e interdependência digital é plausível para Joseph Nye (2014), já que a cooperação em um tema não está necessariamente vinculada a outro. $\mathrm{O}$ autor exemplifica com uma cooperação econômica através da Internet entre China e Estados Unidos, ainda que esses países divirjam sobre Direitos Humanos e controle de conteúdo. Portanto, temos que parte da Internet pode estar mais centrada em regimes e parte centrada em uma governança mais ampla. Definir esses limites a depender da região global, dos países e das corporações transnacionais abre uma futura agenda de pesquisa, assim como observar as movimentações na União Internacional de Telecomunicações (UIT) frente aos novos desafios dos serviços de plataformas e a adesão da tecnologia $5 \mathrm{G}^{9}$. Até aqui, o foco deste artigo recaiu sobre o ocidente: o liberalismo estadunidense e o multilateralismo democrático da União Europeia. Os BRICS também tem um potencial de fazer essa conexão entre as abordagens oriental e ocidental, especialmente através do Estado brasileiro e da Índia, como já foi abordado em declaração conjunta do grupo em 2016 (GRIGSBY, 2016).

A visão de que a governança global da Internet está fragmentada em três abordagens distintas é corroborada por Bruce Schneier em entrevista de 2019:

\footnotetext{
${ }^{7}$ A Grande Muralha Digital da China consiste em um sistema de censura online, onde conteúdos considerados “impróprios" pelo governo são bloqueados, não podendo assim serem acessados em território chinês. Para maiores informações, ver: ECONOMY, E. The great firewall of China: Xi Jinping's internet shutdown. The Guardian, 29 jun. 2018. Disponível em: https://www.theguardian.com/news/2018/jun/29/the-great-firewall-of-china-xijinpings-internet-shutdown. Acesso em 1 fev. 2020.

${ }^{8}$ No entanto, a edição de 2019 do IGF, sediada na Alemanha, contou com uma presença mais significativa de representantes chineses, especialmente acadêmicos.

${ }^{9} \mathrm{~A}$ Internet de quinta geração, ou $5 \mathrm{G}$, amplia o uso da rede e possibilita novas funcionalidades como a disseminação da Internet das Coisas, o que consequentemente aumenta a geração de dados e recursos de poder.
} 
Já está se fraturando em três grandes pedaços. Há a União Europeia, que é atualmente o super poder regulador. Há países totalitários como China e Rússia, que estão usando a Internet para controle social. E há os Estados Unidos, que está permitindo as companhias de tecnologia criarem qualquer mundo que elas acharem mais lucrativo. Todos estão exportando suas visões para países receptivos. Para mim, a questão é quão severa será essa fratura. (SCHNEIER apud THOMSON, 2019, tradução nossa).

O temor de uma fragmentação total da Internet foi uma dos focos do IGF 2019, sediado em Berlim, cujo tema foi "Um mundo, uma Internet, uma visão". Seguindo o modelo iniciado em 2018 na França, onde pela primeira vez houve participação de líderes de alto-nível, a edição de 2019 também contou com discursos do Secretário-Geral da ONU, António Guterres, e da chanceler alemã Angela Merkel. A chefe de governo enfatizou o multilateralismo, seguindo a linha colocada por Emmanuel Macron no ano interior, porém reforçando a necessidade do envolvimento de outros stakeholders, especialmente a sociedade civil e o setor privado. Segundo Merkel, a Internet não pode ser moldada apenas por Estados. Ela também fez uma conceitualização a respeito da "soberania digital", geralmente identificada com isolamento e censura (o termo é bastante utilizado por representantes chineses para se referirem ao modo com a China governa a Internet em seu território). Na visão da chanceler, "soberania digital" diz respeito a cada indivíduo e a sociedade como um todo determinarem, por si mesmos, como será o desenvolvimento da Internet, ou seja, ela relaciona soberania com autonomia (MERKEL, 2019).

Já Guterres abordou os desafios a serem enfrentados em três divisões existentes: há ainda o problema da divisão digital, referente a populações que ainda não possuem acesso à Internet; a divisão social, provocada principalmente pelo funcionamento de algoritmos e; a divisão política, onde fronteiras nacionais e ataques cibernéticos tensionam o sistema internacional. Na visão do Secretário-Geral, a ONU é o local mais propício para tais problemas serem enfrentados, onde pode ocorrer um trabalho conjunto no compartilhamento de expertise e criação de princípios comuns entre os atores (GUTERRES, 2019).

Portanto, este trabalho entende a estratégia posta pela União Europeia a partir de 2018 como uma nova abordagem multissetorial, para se diferenciar da abordagem estadunidense na qual o multissetorialismo favorece sua indústria tecnológica ${ }^{10}$. Os governos europeus ainda querem manter a Internet próxima de seus princípios originais, porém regulando-a para que eles sejam mantidos, não sendo assim "sequestrados" por outros atores (como as plataformas

\footnotetext{
${ }^{10}$ Sobre a preponderância estadunidense na governança global da Internet, ver: CANABARRO, D. Governança Global da Internet: Tecnologia, Poder e Desenvolvimento. Orientador: Marco Aurélio Chaves Cepik. 2014.431 f. Tese (Doutorado em Ciência Política) - Universidade Federal do Rio Grande do Sul, Porto Alegre, 2014.
} 
digitais). Angela Merkel reforçou em seu discurso a questão da liberdade como princípio fundamental da Internet. Desse modo, a União Europeia retoma um papel brevemente exercido pelo Brasil após o caso Snowden, de regular mantendo um caráter multissetorial, para garantir as liberdades e direitos de todos que utilizam a Internet. Especialmente entre 2014 e 2015, o Brasil advogou internacionalmente por uma governança multissetorial da Internet, sem a preponderância de um único Estado (referindo-se aos Estados Unidos). Além de aprovar domesticamente a Lei do Marco Civil da Internet em 2014, aprovou resolução na ONU em conjunto com a Alemanha sobre privacidade na era digital ${ }^{11}$.

Por ora, o setor privado das grandes transnacionais mantém certa preponderância em meio a governança multissetorial, pois as mudanças nos contratos dos serviços sobre uso e processamento de dados pessoais, embora sigam as diretrizes de leis estatais, ainda não possuem mecanismos de transparência relativos à arquitetura dessas plataformas, que aumente a confiança entre o serviço e o usuário; a escolha de uso da criptografia cabe a empresa, podendo restringir o acesso de terceiros aos dados de seus clientes, inclusive por parte do Estado e; as multas até aqui aplicadas nas grandes transnacionais correspondem a valores baixos em relação aos faturamentos dessas empresas, além de não demandar alterações significativas no modelo de negócios baseado nos dados.

Deve-se destacar, porém, o avanço em alguns conceitos e regulações por parte dos Estados, onde os debates no IGF cumprem um importante papel no diálogo e na troca de experiências, especialmente entre reguladores. Construir regulações flexíveis tem sido um dos principais sucessos ao longo dos anos de realização do IGF, cujas discussões inspiraram o próprio Marco Civil brasileiro ${ }^{12}$.

\section{Considerações finais}

A cultura libertária de não intervenção estatal, de uma rede transnacional que independe de fronteiras nacionais, somada a configuração de favorecimento do setor privado comercial nos Estados Unidos, criaram um padrão que com a expansão de empresas e serviços, foi exportado a muitos outros países, criando assim a Internet que conhecemos hoje. Debates

\footnotetext{
${ }^{11}$ Para mais detalhes, ver: PIGATTO, J. O Brasil e a governança da internet: a repercussão do caso Snowden e as ações do governo brasileiro por maior controle internacional da rede. Orientador: Marcelo Passini Mariano. 2017. 40 f. Monografia (Trabalho de Conclusão de Curso em Relações Internacionais) - Universidade Estadual Paulista Júlio de Mesquita Filho, Franca, 2017.

${ }^{12}$ Uma das bases para o Marco Civil da Internet foi o trabalho da Coalizão Dinâmica do IGF chamada "Internet Rights and Principles". Para mais detalhes: Dynamic Coalition on Internet Rights and Principles (IRPC). Internet Governance Forum. Disponível em: https:/www.intgovforum.org/multilingual/content/dynamiccoalition-on-internet-rights-and-principles-irpc. Acesso em: 25 nov. 2019.
} 
opõem diferentes vontades estatais em relação aos princípios internalizados pela comunidade epistêmica da Internet, como do livre fluxo de informações e privacidade (CASTELLS, 2001). O desenvolvimento de novos serviços para a Internet e o surgimento de grandes plataformas como redes sociais ou serviços de e-mail, armazenamento de arquivos, agenda, etc., todos vinculados a uma conta pessoal, demandaram novos questionamentos a partir do modelo de negócios baseado em dados pessoais. Ao invés de o usuário pagar financeiramente por esses serviços, a moeda de troca é a própria coleta de informações que ele gera ao proprietário da plataforma, revelando suas preferências, informações pessoais como endereço, localização em tempo real, tipo de aparelho utilizado para acesso, entre outras.

Após as revelações de Edward Snowden acerca da espionagem massiva norteamericana, o Brasil ocupou um breve papel de liderança na governança global da Internet, advogando pelo multissetorialismo e instituindo uma lei nacional, o Marco Civil da Internet, que elaborado em caráter multissetorial estabeleceu princípios e diretrizes sobre direitos e deveres na rede. $\mathrm{O}$ caso Snowden também possibilitou à União Europeia fortalecer sua lei de proteção de dados, fazendo com que a GDPR, cuja entrada em vigor se deu em 2018, criasse alguns constrangimentos sobre plataformas como Google e Facebook. O mesmo período pós 2013 aumentou, no curto prazo, medidas de autorregulação, a exemplo do aumento de criptografia usada por serviços e plataformas da Internet, inclusive por parte das grandes corporações. Mas o uso indevido de dados pessoais exposto pelo caso Cambridge Analytica, em 2018, fez com que a figura estatal pressionasse o setor privado com mais regulação e controle na rede.

Apesar dos esforços para se estabelecer uma governança global, vemos que ela já está fragmentada em ao menos três principais abordagens utilizadas por atores estatais predominantes no sistema internacional: os Estados Unidos e sua não-interferência que prioriza o livre mercado, consequentemente prioriza suas transnacionais que procuram manter esse status através de lobby e outras formas de pressão; a União Europeia que tenta restringir um pouco desse caráter libertário norte-americano estabelecendo normas e leis para o funcionamento desses serviços digitais; e o caso chinês de intervenção autoritária, não aprofundado neste trabalho. A adaptação das grandes transnacionais a essas diferentes configurações permitem então uma abordagem de autorregulação privada. Ao mesmo tempo, as preocupações estatais com as grandes plataformas deixaram de ser apenas voltadas a políticas econômicas, mas agora também são referentes a questões de direitos fundamentais, ou seja, a lógica nacional é tensionada. Para o Ocidente, vemos que enquanto Estados e outros atores 
procuram definir o que exatamente é uma "soberania digital”, a pergunta que fica é se é possível compatibilizá-la com o multissetorialismo.

AGRADECIMENTOS: este artigo é parte da pesquisa de mestrado intitulada "O papel das corporações transnacionais na governança global da Internet: Google e Facebook nas discussões sobre neutralidade da rede e política de dados (2013-2018)", financiada pela Fundação de Amparo à Pesquisa do Estado de São Paulo (FAPESP), processo 2018/02378-4. Agradeço ao meu orientador, Prof. Dr. Marcelo Passini Mariano, e ao meu colega pesquisador Mark Datysgeld, pelos auxílios e discussões que resultaram neste trabalho.

\section{REFERÊNCIAS}

BELLI, L. 5G e IoT: BRICS precisam de cooperação em cibersegurança. Convergência Digital, 9 set. 2019. Disponível em:

https://www.convergenciadigital.com.br/cgi/cgilua.exe/sys/start.htm?UserActiveTemplate=sit e\&infoid=51649\&sid=15. Acesso em: 12 set. 2019.

CASTELLS, M. The Internet Galaxy: Reflections on the internet, business, and society. New York: Oxford University Press Inc., 2001.

GOETTENAUER, C. Regulação responsiva e a política de segurança cibernética do sistema financeiro nacional. Revista de Direito Setorial e Regulatório, Brasília, v. 5, n. 1, p. 131146, maio 2019.

GOMES, M.; MERCHÁN, C. Governança transnacional: definições, abordagens e agenda de pesquisa. RAC, Rio de Janeiro, v. 21, n. 1, p.84-106, art. 5, 2016.

GRIGSBY, A. Do India and Brazil really moderate China and Russia's approach to cyberspace policy? Council of Foreign Relations, 26 abr. 2016. Disponível em: https://www.cfr.org/blog/do-india-and-brazil-really-moderate-china-and-russias-approachcyberspace-policy. Acesso em: 13 set. 2019.

GUTERRES, A. Discurso na cerimônia de abertura do IGF. In: YOUTUBE. 1 vídeo (transmissão ao vivo). Berlim, 26 nov. 2019

HARRIS, B. Estrutura e governança do comitê de supervisão. Facebook Newsroom, 17 set. 2019. Disponível em:https://br.newsroom.fb.com/news/2019/09/estrutura-e-governanca-docomite-de-supervisao/. Acesso em: 17 set. 2019.

HUREL, L.; LOBATO, L. Unpacking Cybernorms: Private companies as norms entrepreneurs. Giganet: Global Internet Governance Academic Network, Annual Symposium 2017. Disponível em: https://papers.ssrn.com/sol3/papers.cfm?abstract_id=3107237. Acesso em: 25 set 2019. 
HURRELL, A. Complex governance beyond the state. In: On global order: power, values and the constitution of international society. Oxford University Press: New York. 2007. p. 95117.

MERKEL, A. Discurso na cerimônia de abertura do IGF. In: YOUTUBE. 1 vídeo (transmissão ao vivo). Berlim, 26 nov. 2019.

NYE, J. The regime complex for managing global cyber activities. Centre for international governance innovation and the royal institute for international affairs. Paper series, n. 1, maio 2014. Disponível em: http://bit.ly/2yJ0IcI. Acesso em: 28 maio 2019.

PATRICK, S.; FENG, A. Belt and router: China aims for tighter internet controls with digital silk road. Council on Foreign Relations, 2 jul. 2018. Disponível em: https://on.cfr.org/2ZBvekx. Acesso em: 5 ago. 2019.

RADU, R. et al. The evolution of global internet governance: principles and policies in the making. Switzerland: Springer, 2014. 245p.

ROSENAU, J. Governance, order, and change in world politics. In: Governance without government: order and change in world politics. Cambridge University Press, n. 20, 1992. p. $1-29$.

SCHERER, A. et al. Global rules and private actors: toward a new role of the transnational corporation in global governance. Business Ethics Quarterly, v. 16, n. 4, p. 505-532, 2006.

THOMSON, I. Q\&A: Crypto-guru Bruce Schneier on teaching tech to lawmakers, plus privacy failures - and a call to techies to act. The Register, 15 mar. 2019. Disponível em: https://www.theregister.co.uk/2019/03/15/qa_bruce_schneier/. Acesso em: 13 set. 2019.

ZUCKERBERG, M. As the world becomes more complex and governments everywhere struggle, trust in the internet is more important today than ever. Facebook: Mark Zuckerberg, 13 mar. 2014. Disponível em: https://www.facebook.com/zuck/posts/10101301165605491?stream_ref=1. Acesso em: 12 set. 2019.

ZUCKERBERG, M. I've spent most of the past two years focusing on issues like harmful content, elections integrity and privacy. Facebook: Mark Zuckerberg, 30 mar. 2019. Disponível em: https://www.facebook.com/zuck/posts/10107013839885441. Acesso em: 12 set. 2019. 


\section{Como referenciar este artigo}

PIGATTO, Jaqueline Trevisan. Governança transnacional da internet: cooperação internacional ou privatização? Rev. Sem Aspas, Araraquara, v. 8, n. 1, p. 225-239, jul./dez., 2019. e-ISSN: 2358-4238. DOI: https://doi.org/10.29373/sas.v8i2.13357

Submetido em: 21/10/2019

Revisões requeridas: 20/11/2019

Aprovado em: $15 / 12 / 2019$

Publicado em: 30/12/2019 